\title{
Analisando e (des) construindo conceitos: pensando as falsas denúncias de abuso sexual
}

\section{Analyzing and (de)constructing concepts: thinking about the false allegations of sexual abuse}

\section{Marcia Ferreira Amendola}

Doutoranda em Psicologia Social do Programa de Pós-Graduação em Psicologia Social da Universidade do Estado do Rio de Janeiro-PPGPS/UERJ - Rio de Janeiro, RJ, Brasil

\begin{abstract}
Resumo
O objetivo deste artigo é analisar os vários conceitos de violência sexual contra a criança a fim de se discutir as falsas denúncias de abuso sexual envolvendo pais e filhos no contexto da separação conjugal. A proposta visa levar o leitor a explorar e questionar paradigmas e a realizar uma reflexão crítica acerca da prática da avaliação psicológica em casos de denúncia de abuso sexual contra crianças, desafiando-os para uma mudança de postura profissional diante de temas de grande complexidade.
\end{abstract}

Palavras-chave : Abuso sexual contra a criança, Falsa denúncia de abuso sexual, Avaliação psicológica.

\begin{abstract}
The objective of this article is to analyze some concepts of child sexual abuse in order to discuss the false allegations of child sexual abuse in the context of the conjugal separation. The proposal intends to take the reader to explore and to question paradigms and to carry through a critical reflection concerning the practical of the psychological evaluation in cases of child sexual abuse allegations, defeating them for a change of professional position before subjects of great complexity.
\end{abstract}

Keywords : Child sexual abuse, False allegations of sexual abuse, Psychological evaluation.

\section{I ntrodução}

Pela indiscutível seriedade da matéria, a violência sexual contra crianças tem sido tema intensamente debatido por profissionais de saúde e pesquisadores da área e afins, no que se refere à identificação, ao tratamento e à prevenção dos mecanismos de ação e efeitos da violência na criança.

Não obstante existam primorosos trabalhos e estudos sobre 0 assunto em nosso país, estes não exploram, suficientemente, a perspectiva das falsas denúncias de abuso sexual. 
A partir de um levantamento bibliográfico relativo às duas últimas décadas, foi possível verificar que a literatura internacional é extensa e sustenta que as falsas alegações de abuso sexual de pais contra filhos surgem durante a separação (e/ou divórcio), com ou sem disputa judicial pela guarda dos filhos, e são feitas, essencialmente, pelas mães guardiãs, visando ao afastamento do ex-companheiro da vida dos filhos.

Nesse sentido, alguns pais, tanto na Europa quanto nos Estados Unidos e, mais recentemente, no Brasil, vem se mobilizando, por meio de inúmeras Organizações Não-Governamentais (ONG's) e associações de pais, a fim de protestar contra a obstrução do convívio entre pais e filhos, assim como alertar para a problemática das falsas alegações de abuso sexual promovidas por suas ex-mulheres, envolvendo os filhos em comum.

Considerando a possibilidade de existirem falsas denúncias de abuso sexual no contexto da separação conjugal e de a Psicologia haver tomado para si o estudo sobre o fenômeno da violência contra a criança, sendo responsável pela práxis da avaliação psicológica nesses casos, foi desenvolvida uma pesquisa de Mestrado junto ao Programa de Pós-Graduação em Psicologia Social do Instituto de Psicologia da Universidade do Estado do Rio de Janeiro. A pesquisa visou compreender como os psicólogos, que atuam em instituições de referência na avaliação de casos de suspeita de abuso sexual contra criança, desempenham suas atividades.

\section{Analisando e (Des) Construindo Conceitos}

A violência sexual contra criança, também designada: abuso sexual, agressão sexual, vitimização sexual, maus-tratos, sevícia sexual, crime sexual e outros tantos termos utilizados, indiscriminadamente, na literatura como sinônimos, reflete, não apenas uma questão de terminologia, mas, principalmente, uma questão epistemológica, segundo a qual, a complexidade e a diversidade das manifestações da violência, associada à falta de clareza de conceituação, permitem que o fenômeno da violência sexual seja tratado conforme opiniões e ideologias individuais e/ou compartilhadas pela cultura na qual o indivíduo está inserido.

Partindo da origem etimológica de abuso, Faleiros e Campos (2000) concluíram pela definição de abuso sexual como uma situação de transposição de limites, da lei, do poder, de papéis, regras e tabus sociais e familiares, considerando, ainda, que as situações de abuso infringem maus-tratos às vítimas. $\mathrm{Na}$ opinião das autoras, para conceituar abuso sexual contra crianças é preciso compreender a natureza do processo que irá conferir um caráter sexual à violência, salientando que esta: (a) adultera as relações socioafetivas e 
culturais entre adultos e crianças, transformando-as em relações genitalizadas, erotizadas; (b) inverte a natureza dessas relações definidas socialmente, tornando-as não-protetoras; (c) gera confusão com relação à representação social dos papéis dos adultos (de pai, mãe, irmão/ã, avô/ó, tio/a, professor/a, etc.), implicando em perda de legitimidade de seus papéis e funções sociais; (d) confunde os limites intergeracionais.

As autoras admitem, no entanto, que não há um conceito único e preciso para se aplicar ao abuso sexual, de modo que estudiosos da temática assentem que o atual conhecimento acerca da violência sexual ainda está em processo de elaboração devido à sua complexidade e controvérsia (Assis, 1994; Minayo, 1999; Gonçalves, 2003; Ribeiro, Ferriani \& Reis, 2004).

Nesse contexto, Gonçalves (2003) alerta que é preciso cuidado ao se analisar todo e qualquer comportamento que, hipoteticamente, possa ser considerado violento, pois, tanto a expansão do conceito de violência sexual quanto a sua contração serão percebidos a partir do valor moral que os compõem. Isso permite questionar se um beijo dado na boca de uma criança por sua mãe seria um comportamento desviante, patológico, um abuso ou uma demonstração de amor. Válido também o é aplicar este questionamento ao beijo dado pelo pai.

A psicóloga Faiman, em entrevista à "Revista Crescer - em família" (jul/2004), ressaltou que 0 fato de fixarmos determinados comportamentos para definir abuso sexual poderia levar o profissional a cometer erros de interpretação. Destacou ser imprescindível levar em conta o contexto, os hábitos familiares, pois são os fatores que irão conferir sentido às ações, incluindo a nudez, que pode ter conotações, absolutamente, distintas, dependendo da família.

Desta forma, se o comportamento dirigido a uma criança estiver dissociado do contexto cultural, existe o risco deste ser interpretado como um desvio, uma doença e/ou um fracasso de adequação às regras sociais. Portanto, a violência sexual não deve ser entendida como ato isolado, "psicologizado pelo descontrole, pela doença, pela patologia, mas como um desencadear de relações que envolvem a cultura, o imaginário, as normas, o processo civilizatório de um povo" (Faleiros, 1998, p. 267).

Essa concepção, também compartilhada por outros autores, compreende a violência sexual como um fenômeno de natureza sociohistórica e cultural, isto é, influenciado de maneira intensa pela cultura e pelo tempo histórico em que ocorre, devendo ser analisado no contexto em que está inserido (Finkelhor, 1979; Garbarino; Gilliam, 1981; Haugaard; Repucci, 1988; Flores, 1998; Junqueira, 1998; Gonçalves, 1999, 2003; Faleiros; Campos, 2000; Sanderson, 2005). 
Haugaard e Repucci (1988), ao colocarem em discussão essas considerações, afirmaram que há um grande número de atos, vagamente definidos, que vêm sendo utilizados para conceituar abuso sexual. Problema também apontado por Sanderson (2005) que declarou ser muito amplo o espectro de atos sexuais empregados para caracterizar uma ocorrência de abuso sexual contra a criança, pois inclui comportamentos de contato tanto quanto de não-contato. Fato que afeta a caracterização de abuso sexual, refletindo, diretamente, nas estatísticas que analisam a extensão ou incidência do problema, dada a variabilidade das informações.

Constata-se, portanto, que existe uma enormidade de fatores ou atributos para definir abuso sexual, de forma que pesquisadores e profissionais tendem a adotar critérios e definições compatíveis com suas afinidades teóricas a fim de nortear seus trabalhos.

Por sua vez, a dificuldade não se restringe à conceituação, mas, principalmente, à identificação da ocorrência de violência sexual na criança. Considerando que, não raro, o abuso sexual ocorre em tenra idade, a criança tenderia a não reconhecer a situação como abusiva, critério a ser atribuído pelos demais familiares e profissionais de saúde. Nesse sentido, a revelação do abuso sexual se configura em um mecanismo bastante complexo para a criança abusada, pois esta pode vir a apresentar uma ambiguidade emocional em relação ao adulto abusador, visto como mais atencioso do que qualquer outra pessoa (Miller, 2002).

Alguns autores entendem que as crianças, na tentativa de anular as experiências abusivas, entrariam em estado alterado de consciência (dissociação), decorrendo uma série de comprometimentos psicológicos e comportamentais (FARINATTI; BIAZUS; LEITE, 1993; Caminha, 2000; Furniss, 2002; Habigzang; Caminha, 2004).

Contudo, nem sempre é possível identificar as consequências de um abuso sexual na criança - o que torna o processo de diagnóstico dificultoso e sujeito a erros de interpretação pelos profissionais.

Diante desse desafio, estudos têm sido desenvolvidos, tanto pelas ciências médicas quanto pelas psicológicas, com a finalidade de determinar quais os possíveis comprometimentos psicológicos e comportamentais advindos da exposição de crianças ao abuso sexual. Porém, antes de se caracterizar a sintomatologia do abuso sexual na criança é preciso aludir aos fatores que influenciam na formação do dano psicológico causado por essa experiência (AMAZARRAY; KOLLER, 1998). Nesse sentido, Rouyer (1997), Koller (2000) e Sanderson (2005) destacam o contexto no qual o abuso sexual teria ocorrido como um dos principais fatores a ser considerado. $\mathrm{Na}$ opinião de Sanderson (2005, p. 202), é fundamental que o profissional contextualize a situação, conhecendo a criança, sua família e seu mundo social, assim como sinais e sintomas observados na criança a fim de evitar julgamentos precipitados da ocorrência do 
abuso, "uma vez que um diagnóstico errado ou prematuro pode causar trauma desnecessário tanto na criança quanto na família".

Logo, De Young (1986), Haugaard e Repucci (1988), Gardner (1991), Green (1993), Ceci e Bruck (2002) e Sanderson (2005) ressaltaram o cuidado que se deve ter ao utilizar as informações disponíveis sobre as consequências do abuso sexual contra a criança, pois são fruto de uma ampla variedade de causas e contextos, nem todos relacionados com a ocorrência de abuso sexual. Os autores concluem que não há padrão de comportamento e sintomas específicos que ocorram em todas ou quase todas as crianças abusadas, tampouco existem indicadores que, seguramente, revelem a ausência de abuso sexual em crianças, sendo inviável e imprudente a generalização dos mesmos. Isso ocorre porque os indicadores comportamentais e de personalidade, raramente, diferenciam quando são decorrentes de traumas ocasionados pelo abuso sexual de quando são produzidos por diferentes tensores na vida de uma criança, ou mesmo de comportamentos esperados para crianças de determinadas faixas etárias.

Desta forma, identificar comportamentos sexuais em crianças em idade pré-escolar, como: masturbação, exibicionismo ou ferimentos nos genitais, não implica, necessariamente, a ocorrência de abuso sexual; tampouco a manifestação de sintomas ligados à depressão, como: tristeza, insônia, apatia e retraimento social.

De acordo com Wallerstein e Kelly (1998), há muitos casos de filhos de pais separados que apresentam reações físicas ou as têm exacerbadas com a proximidade do horário de visita, ansiosas por rever o genitor não-guardião. Manifestações estas que tendem a desaparecer por ocasião da interação entre ambos. Outras, por sua vez, reagem com hostilidade, recusando-se a ir com o genitor, reflexo da acirrada rivalidade e/ou agressividade presente na relação entre os pais, que, não raro, disputam a atenção da criança com sedução ou ameaças.

Entretanto, tais reações tendem a ser, equivocadamente, interpretadas como sintomas de medo, decorrente de uma suposta ocorrência de abuso sexual. Dessa forma, é possível deduzir que a sintomatologia apresentada pelas crianças deve ser observada em concomitância a um repertório de fatores, tais como o contexto social e familiar em que vivem.

\section{Problematizando o Tema da (Falsa) Denúncia de Abuso Sexual Contra a Criança}

\section{O Depoimento}


Diante das dificuldades para estabelecer a materialidade baseada em evidências físicas ou comportamentais, nos casos em que se alega a ocorrência de abuso sexual contra a criança, o depoimento desta última tem adquirido status de matéria probatória na processualística civil e penal, a despeito das reservas impostas por fatores pertinentes à condição especial de pessoa em desenvolvimento. Desta forma, a palavra da criança, se harmônica com as demais provas dos autos, vem sendo amparada pela jurisprudência, a partir da compreensão de que os crimes contra os costumes, normalmente, ocorrem na clandestinidade, sem testemunhas.

Tal fato tem possibilitado a articulação entre a Psicologia e o Direito, no qual o profissional psicólogo, ao procurar atender à demanda do poder judiciário pela produção da verdade a respeito de um fato ou fenômeno (Miranda Jr., 1998), vem operando na busca pela revelação do abuso sexual.

O termo revelação, portanto, ganhou aspectos de intervenção realizada por profissionais de Psicologia e de Serviço Social no trato com crianças, supostamente, vítimas de abuso sexual - a qual denominou-se Entrevista de Revelação ou Estudo de Revelação. De acordo com os autores estudados, essa técnica tem por objetivo criar um ambiente facilitador que permita à criança revelar o abuso sexual a partir da produção discursiva, lúdica e gráfica, sem desenvolver sentimentos de culpa ou vergonha.

Furniss (2002, p.177), ao descrever essa técnica de revelação, demonstra certa tendenciosidade no trato de questões relativas à prática profissional em casos de suspeita de abuso sexual, pois o autor orienta os profissionais a iniciar a entrevista com a "permissão terapêutica explícita para revelar". Isso significa que o propósito do psicólogo durante a entrevista é, necessariamente, fazer com que a criança relate o abuso sexual, presumidamente, sofrido. Segundo Furniss (2002, p. 177), é preciso enviar, de maneiras variadas e repetidas, a mensagem: "Eu sei que você sabe que eu sei". Ao final de todas as considerações, se a criança ainda não estiver motivada a revelar, o autor argumenta que ela possa estar assustada demais, provavelmente, por ameaças do abusador ou possa estar resistente. Apesar de declarar que é preciso estar atento para o fato do abuso sexual não haver ocorrido, Furniss (2002) insiste que o profissional não deve aceitar quando a criança nega a ocorrência do abuso, considerando que a negação seja consequência das ansiedades e medos desta em revelar. Seguindo essa lógica, a autora sustenta que, mesmo quando o silêncio da criança persiste, o profissional deve se antecipar e presumir a alegação de abuso sexual como verdadeira. $\mathrm{Na}$ análise do autor, o ato de insistir para que a criança revele o abuso sexual se justificaria, pois estaria baseado na crença de que as crianças que negam a ocorrência do abuso sexual podem estar mentindo. Contudo, o autor admite que a criança possa mentir ao 
revelar um abuso sexual, acusando, falsamente, um membro da família.

Trata-se, seguindo essa lógica, de uma situação em que, apesar da não ocorrência do abuso, o adulto responsável por seu atendimento não outorga legitimidade às palavras da criança, apenas quando estas palavras correspondem à confirmação do suposto abuso essencial para o sucesso da entrevista de revelação.

Posicionamentos contrários ao de Furniss (2002) foram levantados por Bruck, Ceci e Shuman (2005), a partir de resultados obtidos de uma série de pesquisas por eles analisadas. Os autores declararam que, se a revelação da criança transcorrer na forma de pequenos fragmentos promovidos por entrevistas diretivas ou jogos de representação, nos moldes que Furniss (2002) sugere, os autores acreditam que esta possa se dar como resultado de um processo de sugestão, portanto suscetível a distorções.

Tal conclusão também foi sustentada por Schacter (2003), pesquisador que analisa possíveis causas, consequências e imperfeições da memória. Para o autor, as respostas de crianças a perguntas específicas - em que, não raramente, recebem elogios pelos entrevistadores quando a informação desejada é apresentada e desapontamento e reprovação quando as crianças não respondem de acordo com o esperado - não podem ser interpretadas como recordação de uma situação de abuso sexual. Diante desse processo, a criança poderia ser conduzida pelas expectativas e crenças do profissional entrevistador.

Ainda, de acordo com essas pesquisas, a produção da verdade, pelo testemunho da criança, pode estar associada, diretamente, a vários tipos de pressões sociais, no qual se admite que a criança possa mentir para proteger ou agradar uma pessoa da qual depende afetivamente. Sendo assim, nas circunstâncias de separação conjugal, é possível supor que a criança pode se manter fiel às alegações da mãe guardiã que acusa o ex-companheiro, ao invés de apenas negar o abuso para proteger o seu suposto agressor. Ambas as alternativas são viáveis, se forem consideradas as explicações dos autores, dependendo apenas de quem a criança protege ou quer agradar, ou seja, de quem a criança irá estabelecer vínculos de lealdade.

Para Chauí (2000, p.435), os vínculos de lealdade podem ser forçados por coação externa. "[...] poderia acontecer que para forçar alguém à lealdade seria preciso fazê-lo sentir medo da punição pela deslealdade, ou seria preciso mentir-lhe para que não perdesse a confiança em certas pessoas e continuasse leal a elas".

Outro ponto de vista seria pensar que a criança também pode mentir na intenção de corresponder com o que percebe ser do agrado do adulto. Assim, a criança poderia acrescentar comentários, tanto para atrair a atenção do profissional que a entrevista quanto para agradá- 
lo. Com efeito, não é de se surpreender que as crianças, após prolongadas entrevistas sugestivas sobre experiências sexuais, comecem a perceber que a discussão sobre esses temas seja, não apenas aceitável, mas, realmente, desejável (Ceci; Buck; Rosenthal, 1995).

Cárdenas (2000), De Young (1986) e Gardner (1991) lembram que, mesmo não havendo intencionalidade no relato da criança, seja porque ela reproduz o que um adulto de sua confiança tenha Ihe instruído a dizer ou a acreditar, seja porque o adulto esteja convencido de que a criança foi abusada, o paradigma criança nunca mente deve ser, necessariamente, analisado.

De acordo com Piaget (1994), é na fase da infância (até os sete anos de idade) que ocorre o desenvolvimento moral na criança nas suas relações com o adulto, no qual as regras estabelecidas, de modo determinado e imposto, advém de uma ordem exterior, portanto, de seus pais, educadores e demais adultos de sua confiança. Este estágio, denominado heterônomo (oposto a autônomo), faz com que a criança conceba a regra como algo correto, que deve ser seguido e obedecido, do contrário, haverá uma punição. Logo, admite-se que, na aprendizagem social (aquisição gradual de valores, linguagem, costumes e padrões culturais e sociais), ao estar subordinada à autoridade parental, a criança assimila os valores morais dos pais em seu processo de desenvolvimento. Desta forma, a relação adultocriança está pautada na coação, mas também no egocentrismo, no qual a criança procura imitar o que os adultos fazem, sem apresentar consciência da atividade como algo social, em função de sua capacidade cognitiva estar em desenvolvimento. Assim, a criança, não dispondo de recursos cognitivos para perceber e coordenar os diferentes pontos de vista, pratica a regra por meio da imitação ou da repetição.

De acordo com Maluf, em reportagem à "Revista Escola" (2004), a criança (até 06 anos de idade), do ponto de vista cognitivo, não possui desenvolvimento capaz de diferenciar um engano intencional (mentira) de seus jogos de faz-de-conta (fantasia), ou se o que the transmitem é verdade ou mentira do ponto de vista factual. Para a psicopedagoga, a criança, até essa idade, não tem um compromisso com a realidade.

Se a criança, nessa fase do desenvolvimento, em que os valores morais são assimilados, aprende que, para evitar a punição, deve estar atenta para os interesses dos adultos, não os contrariando ou desobedecendo, tal comportamento tende a causar um constrangimento na criança, fazendo-a, em certos momentos, ocultar a realidade, como apresentado na fala de duas crianças atendidas pela equipe de residentes de Psicologia do Hospital Universitário Pedro Ernesto - HUPE/UERJ . 
[1] Minha mãe falou que meu pai é mau, que faz maldade (...) ela disse que vai bater na minha cara se eu falar que gosto dele e da vovó (Criança A., sexo feminino, 4 anos, apud Amendola, 2004, p.157).

[2] Olha só: eu estava lá com meu pai, ele me deu banho e botou esse dedo, não... esse... agora não sei qual dedo minha mãe falou; foi esse dedo na minha perereca, porque ele é um monstro, não merece a princesinha. Pronto, tia, agora a gente pode brincar? (Criança E., sexo feminino, 4 anos, apud Nogueira e Sá, 2004, p.92). Neste caso, Nogueira e Sá (2004) alertam que a coação e o constrangimento psíquico impostos pela genitora que faz uma falsa denúncia de abuso sexual constituem uma prática de violência psicológica ou emocional, cuja intenção é vencer a resistência da criança e levá-la a aceitar o abuso sexual, contribuindo para a distorção da realidade e consequente perda de diretrizes do que é certo ou errado. Com efeito, a criança perderia sua capacidade de aprender a dizer não (de contrariar o adulto) e de ser coerente com o que pensa e sente, a fim de evitar a punição ou de sofrer com a ameaça de abandono físico e emocional da mãe, passando a reproduzir o discurso e pensamento desta.

Nas palavras de Nogueira (2002, p.99):

[...] a realidade psíquica da criança estava completamente emaranhada com a da mãe, onde a fala da criança tinha de corresponder à verdade da fala do adulto, abrindo mão da própria verdade de sua fala para corresponder às exigências maternas.

Nesse sentido, Gardner (1991) é contumaz ao afirmar que os profissionais, que buscam na palavra da criança a verdade factual para a comprovação de um abuso sexual, negligenciam o fato de que os filhos são influenciados pelos genitores, especialmente, pelo genitor guardião (mãe) quem, geralmente, é o responsável pela acusação e intenção de afastamento de pais e filhos. O autor explica que, no caso de haver litígio, o genitor guardião seria capaz de programar os filhos para acreditar em uma história de maus-tratos e violência. Critica, ainda, o processo utilizado por esses profissionais na avaliação de crianças menores de 5 anos quanto ao entendimento sobre os conceitos de verdade e mentira, dada a falta de respaldo científico e metodológico.

Não obstante às considerações, ao discutir a palavra da criança na qualidade de testemunho do seu próprio abuso sexual, Thouvenin (1997, p. 98) ressaltou que é o especialista quem transforma esta palavra em um discurso educativo, médico, psicológico ou judiciário. A autora acrescentou que "o modo de colher o testemunho da criança não é óbvio, nem a escolha do modo de intervenção que se seguirá". Desta forma, a transformação da palavra da criança pela interpretação dos profissionais de Psicologia fundamenta-se no princípio, cada vez mais difundido pelos psicólogos, de que são 
capacitados para traduzir, decodificar, preencher as lacunas e os nãoditos de crianças supostamente abusadas. Assim, a palavra da criança, transformada e modulada pela interpretação do adulto que Ihe dá assistência, não raro, tende a expressar as impressões pessoais desse adulto, que não hesita em condenar o autor do suposto abuso (Thouvenin, 1997).

Além da interpretação, Schacter (2003) afirmou que os profissionais também costumam elogiar e a dar prêmios às crianças quando estas Ihes fornecem a informação esperada ou considerada certa e manifestam desapontamento e reprovação quando as crianças não Ihes correspondem às expectativas. Por sua vez, nas circunstâncias em que as perguntas não são respondidas pelas crianças, os profissionais tendem a repeti-las, incentivando-as a especular sobre 0 que poderia ter ocorrido.

Nessas condições, estudiosos afirmam que as crianças podem ser manipuladas por seus entrevistadores a partir do uso de técnicas para revelação do suposto abuso sexual, como: fantoches, bonecos e desenhos - que, por sua vez, não possuem respaldo científico para validar diagnósticos de abuso sexual contra a criança (Lowry, 1994; Wakefield; Underwager, 1995; Campbell, 1998; Ceci; Hembrooke, 1998; Coleman; Clancy, 1999; Schacter, 2003; Ceci; Bruck, 2002).

A partir desse entendimento, fica evidente que a entrevista para revelação do abuso sexual é alvo de críticas quanto à sua cientificidade e aplicabilidade, configurando-se em um tema controverso, com propensão para suscitar uma diversidade de opiniões a seu respeito.

Dos autores citados, verifica-se que a preocupação se concentra na natureza indutiva desse processo, de modo que é possível concluir que não existe um grau de credibilidade absoluta para o testemunho da criança, geralmente, atravessado pelo discurso e interpretação de psicólogos movidos pelo clamor da proteção à criança, pela orientação teórica, pelas hipóteses prediletas, em detrimento da dinâmica da personalidade do sujeito e do contexto social e familiar em que está inserido.

Nesse enquadre, a atuação do profissional pode transformar os atendimentos em mais um instrumento de violência, quando a criança que não foi abusada (como aquela que foi abusada) é, insistentemente, inquirida em busca de respostas que corroborem o abuso. Situação incompatível com a manutenção dos direitos das crianças e familiares e com deveres e postura profissional dos psicólogos. (Njaine, Souza, Minayo; Assis, 1997; Gonçalves; Ferreira, 2002; Gonçalves, 2003).

Nesse sentido, a questão da confiabilidade, atribuída à precisão do avaliador em relação aos resultados de sua intervenção, expressos em laudos psicológicos é questionada. Para Rauter (1989), os instrumentos utilizados na avaliação psicológica constituem-se, por 
vezes, formas de reproduzir os estereótipos e preconceitos que perpassam a concepção dos profissionais acerca da violência sexual contra a criança.

Furniss (2002, p.167), apresentando-se mais cauteloso, sugeriu que, a despeito de todos os cuidados observados pelos psicólogos e demais profissionais, houvesse uma tendência deste a simpatizar com as crianças, imediatamente, após a denúncia de abuso sexual pelas mães. Uma ação prematura, capaz de gerar duas possíveis consequências: uma acusação de abuso sexual sem fundamentação adequada ou sem determinar seu valor factual, provocando um processo investigativo precário e a "prevenção de crime promotorade-crime" (p.191), ou seja, uma acusação infundada de abuso sexual, seja pela leitura equivocada dos sinais da criança, seja pela falsidade da denúncia declarada pelo responsável (guardião, geralmente, a mãe).

Nesta circunstância, o autor partiu do princípio que alguns profissionais, ao agir de forma precipitada, poderiam estar identificados com a criança vítima de abuso sexual, comprometendo a abordagem terapêutica, além de influenciar o trabalho de outros profissionais. Recomendou, portanto, que todo profissional de saúde adote, a priori, entrevistas com o acusado e com os familiares da criança, para, somente após, seguir com a notificação que vise à responsabilização do suposto abusador. Desta forma, evitar-se-ia que a denúncia se transformasse em arma na inculpação de inocentes, incorrendo na exposição prematura e prejudicial da criança e seus familiares.

\section{O Contexto}

Observa-se que circula, tautologicamente, entre os profissionais de Psicologia e do Direito, uma lógica interna de acusação que transmite a seguinte proposição: se à mãe, naturalmente, predisposta a cuidar da criança, cabe a verdade em relação à denúncia de abuso sexual, logo, ao pai, que nega a autoria deste abuso, resta a mentira. A consequência mais provável dessa lógica, fundamentada em "versões canônicas" (Cárdenas, 2000, p.1), é que o profissional se antecipe às evidências e se abstenha do compromisso de ouvir o pai acusado ou de ouvi-lo sem tendenciosidade.

Tal lógica remete à ancoragem sociohistórica em que a mãe é vista, com base nos dispositivos higiênicos fundadores da família nuclear moderna e na tradição cultural do instinto materno - produto do discurso psicanalítico em ascensão nos séculos XIX e XX - como a responsável pelo desenvolvimento e proteção dos filhos, enquanto $o$ pai é visto como figura que exerce autoridade, estabelecendo uma relação periférica e intermitente com os mesmos. 
A partir da difusão desses preceitos, a mulher ganhou autonomia para exercer seu papel de mãe e guardiã sem ser questionada, perpassando a idéia de mulher auto-suficiente nos cuidados com os filhos, portanto, incapaz de prejudicar os mesmos.

Todavia, com a possibilidade de separação, novas relações familiares se configuraram na sociedade brasileira, tornando necessária a redefinição dos papéis de cada um dos membros da família dentro das observâncias dos direitos e deveres de filiação e aliança (Brito, 2002a).

Assim, com as transformações ocorridas na sociedade contemporânea, foi preciso que a Legislação referente ao Direito de Família aplicasse o princípio da igualdade de direitos entre homens e aos efeitos da separação judicial na vida dos filhos. O Código Civil Brasileiro, Lei 10.406 de 2002 (BRASIL, Novo Código Civil, 2003), atendendo a tais princípios constitucionais, substituiu o poder decisório do marido pela autoridade conjunta (direitos e deveres) dos cônjuges, denominada "Poder Familiar" (Art. 1.630 a 1.638 do Código Civil de 2002).

Para a juíza Comel (2004), o poder familiar corresponde aos pais que, em posição de igualdade jurídica, têm os mesmos direitos e responsabilidades no cumprimento de suas atribuições para com a pessoa dos filhos e a prática desses mesmos direitos, especialmente, quando não mais vigora a união conjugal.

No entanto, diante da prerrogativa do Código em atribuir a guarda dos filhos ao genitor que possuir melhores condições, sem, contudo, estabelecer os critérios a serem observados na escolha do guardião, a disputa pela guarda, mesmo que prevista na legislação, favorece o afrontamento dos pais, que podem apelar para que seus representantes legais reúnam provas que desabonem a conduta do outro. Nesse confronto, a escolha do guardião recai na divisória entre o melhor e pior genitor, entre o vencedor e o perdedor, no qual “despreza-se o fato de que está em jogo o futuro e o desenvolvimento de filhos comuns, colocados no lugar de 'pomo da discórdia', ou ainda levados a tomar partido de um dos pais" (Brito, 2002b, p.436).

Assim, quando colocadas no lugar de guardiãs, algumas mães buscam dificultar o relacionamento entre pais e seus filhos, provendo, em situações extremadas, alegações infundadas de abuso sexual.

A partir dessas alegações, o ordenamento jurídico brasileiro ressalta que, na hipótese de opressão ou abuso sexual pelos pais ou responsáveis, os direitos das crianças e dos adolescentes devem ser protegidos. Nesse sentido, os operadores do Direito têm recorrido à aplicação do Art. 130 do Estatuto da Criança e do Adolescente (BRASIL, Estatuto da Criança e do Adolescente, 2003), mesmo nos casos em que o pai acusado não mais reside com a criança, para autorizar, liminarmente, o afastamento da criança de seu suposto 
agressor, como medida cautelar, por meio da suspensão da visita. Uma interpretação da Lei que tem por objetivo manter o caráter protetivo da medida até que a questão reste completamente esclarecida.

Com efeito, o que tal interpretação sustenta, no tocante à denúncia de abuso sexual contra a criança, é a formação e manutenção, invariável, de uma aura de suspeição que circunda o acusado, assim como da presunção pela existência de dolo, urgindo que a prioridade recaia à garantia dos direitos da criança.

Neste caso, percebe-se que muitos afastamentos de pais e filhos têm sido promovidos por ordem judicial mediante análise de laudos psicológicos de profissionais que se remetem apenas à fala da acusação e da suposta vítima. Tal fato fundamenta-se, de forma equivocada, à lógica da acusação, privilegiando a versão canônica de que a mãe sempre diz a verdade.

Segundo Njaine, Souza, Minayo e Assis (1997), a exclusão do pai acusado torna esta intervenção psicológica propensa a erros de interpretação pelos profissionais, em virtude de restringir-lhes o alcance do olhar somente às informações que Ihes são prestadas por uma das partes. Portanto, tal fato determina a emissão de conclusões parciais, a despeito de o psicólogo entender que a criança revelou o abuso.

\section{Afastamento e Alinhamento}

Como discutido anteriormente, Nogueira e Sá (2004) alertam que, mesmo quando a criança revela o abuso sexual ao profissional de Psicologia, suas palavras podem estar configuradas nos moldes do pensamento materno, dada a influência desta última no processo de aprendizagem social das crianças. Nestes casos, verifica-se que a prática coercitiva materna pode ser reforçada pelo profissional de Psicologia quando impõe à criança a responsabilidade pela revelação e confirmação do abuso sexual.

Nesse contexto, alguns autores são criteriosos em relação ao afastamento do pai do convívio da criança, exclusivamente, a partir de uma suspeita de abuso sexual, pois tal atitude pode ser considerada prematura, por conseguinte, prejudicial, não apenas à relação pai e filho, como também ao próprio processo de investigação (Sgroi, 1982; Njaine, Souza, Minayo; Assis, 1997; Furniss, 2002; Silva, 2002; Cesca, 2004; Sanderson, 2005).

Segundo Wallerstein e Kelly (1998, p.95), o afastamento entre pai e filhos tem o potencial para provocar uma situação de "alinhamento", definido como um relacionamento que ocorre quando um dos genitores se empenha em formar alianças e coalisões com os filhos com o propósito de romper os vínculos estabelecidos com o outro 
genitor. Os filhos, ao se identificarem com o sofrimento, raiva ou apelos do genitor guardião, privilegiariam esta relação, desferindo ataques ao outro genitor.

Para as autoras, a circunstância da separação conjugal dos pais tem o potencial de gerar um padrão de respostas emocionais nas crianças, que se apresentariam bastante sensibilizadas e vulneráveis, podendo se deixar envolver pela raiva do genitor guardião em relação ao outro, tornando-se aliadas fiéis contra este último. Acrescentam, ainda, que tais crianças apresentar-se-iam, simultaneamente, carentes de afeto e fascinadas com a sedução e excesso de atenção dado pelo genitor responsável pelo alinhamento.

A teoria explicativa do alinhamento, tendo a raiva como elemento central, postula que as mães guardiãs expressam a hostilidade pelo ex-companheiro, caluniando-o na presença dos filhos, que são convidados a participar desses ataques. Mantendo uma aparência de "ordem interna psicológica" (Wallerstein; Kelly, 1998, p.41), estas mães buscariam formar alianças com os filhos, inserindo-os no caos do divórcio.

As pesquisadoras esclarecem ainda que, diante da incompetência da família pós-divórcio para lidar com seus conflitos, os filhos assumiriam, de forma ativa, a tarefa de preservar o relacionamento afetivo com o genitor mais fragilizado ou magoado com a separação, normalmente a mãe, tornando-se seus "aliados, confidentes e salvadores" (Wallerstein; Kelly, 1998, p.33). As mães, por sua vez, ao sentirem as visitas paternas como disruptivas, passariam a impor obstáculos na concretização destas, seja convencendo os filhos de que os pais não mais os amam, seja ameaçando-os com o abandono materno (quando passariam a tratar os filhos com gestos de desprezo e/ou chantagens). Concomitantemente, puniriam os excompanheiros, promovendo a destruição do relacionamento paternofilial.

A ameaça não verbalizada para muitas das crianças era que seu relacionamento com a mãe poderia correr perigo se elas mantivessem certa lealdade ao pai. Mesmo se a criança se aliasse à mãe, nós percebemos uma deterioração na capacidade dessas mães de prestar os cuidados diários e confortar os filhos. Além disso, quase não havia sensibilidade, nessas mães e pais, à angústia da criança (Wallerstein; Kelly, 1998, p.42).

Outra teoria que aborda o tema, conhecida por Síndrome de Alienação Parental (SAP), foi definida pelo médico psiquiatra, Richard Gardner, no ano de 1985. De acordo Gardner (1992), a SAP consistiria em um distúrbio psicoafetivo que a criança manifestaria ao torna-se aliada do genitor que detém a guarda contra o genitor nãoguardião.

Preconiza a teoria que filhos de pais separados podem vir a formar alianças com o genitor guardião, manifestando um comportamento 
exagerado de rejeição e depreciação direcionado ao genitor não guardião, a quem a criança mantinha relações de afeto.

Segundo o autor, sendo a mãe a guardiã preferencial dos filhos, esta é considerada o genitor alienador - responsável pelo processo de "programação mental" (p.73) dos filhos - que, imbuída da intenção de exilar o pai da vida dos mesmos, utilizar-se-ia de ameaças e punições, obrigando os filhos a se aliarem a ela contra o pai, difamando-o.

Nesta síndrome, no entanto, constata-se, forte tendência a patologizar os comportamentos no âmbito das relações familiares pós-divórcio, o que não se observa nas circunstâncias do alinhamento. Neste, é possível observar crianças apresentando resistência para estar com os pais, uma oportunidade às mães apelarem para o direito de os filhos serem ouvidos em seus pedidos (para não verem os pais). Com efeito, entende-se que a opinião expressa pelos filhos geralmente reflete a vontade da mãe, de modo que as crianças não podem ser consideradas sujeitos de direito, mas assujeitadas à mãe.

Nessa linha de pensamento, entende-se que as investidas da mãe guardiã para afastar o pai dos filhos podem conduzir à fabulação do abuso sexual, a partir de distorções de fatos triviais, como um banho ou uma higienização íntima feita pelo genitor na criança ou, de forma mais incisiva, podem induzir sinais físicos do trauma sexual para provar suas alegações de abuso sexual. Por conseguinte, a interrupção das visitas, pela imposição de medida protetiva, teria a vantagem de garantir à mãe tempo para fazer a criança acreditar, falar e agir como se vítima do abuso fosse.

Atentando para o fato de que o abuso sexual contra crianças é violência de difícil detecção, a palavra da mãe e a avaliação da criança, sujeitada à autoridade e ameaças maternas, tornam-se evidências que se complementam na condenação do pai. Sendo assim, quando o psicólogo e/ou a instituição, encarregado de realizar uma avaliação de casos de suspeita de abuso sexual, exime-se de atender ao acusado, cerceando-Ihe a palavra, também extrai da análise, parte que integra o contexto de vida da criança. Evita-se, assim, a dúvida, o questionamento, a crítica reflexiva fundamental no trabalho do psicólogo, para se valorizar a presunção e o preconceito. Dessa forma, perguntas como: estará o pai acusado dizendo a verdade sobre sua inocência?; estará a criança sendo coagida pela mãe?; estará esta mãe mentindo e acusando o pai para afastá-lo de seu filho? - ficarão sem respostas, pois deixaram de ser pensadas.

Por esta razão, o psicólogo não deve assumir a posição daquele que sabe. Tal postura traduz uma onipotência que retira do profissional a flexibilidade e a imparcialidade do pensamento, comprometendo a seriedade do trabalho. 
Na opinião de Arzeno (1995) e Yehia (2002), os conhecimentos teóricos, técnicos e os da própria experiência de trabalho ou de vida jamais substituem a história das pessoas envolvidas, sendo "apenas um outro ponto de vista" que merece ser analisado (Yehia, 2002, p.119).

\section{Algumas palavras para finalizar}

O abuso sexual é uma realidade indubitável e assim o é a falsa acusação de abuso sexual contra a criança promovida pelo genitor guardião no contexto da separação conjugal litigiosa, dada a sua constatação prática.

Partindo da análise dos estudos teórico-científicos apresentados, reconhece-se que as crianças não estão, geralmente, inclinadas a criar declarações falsas do abuso sem que haja a influência parental ou de um adulto a quem estabelece relações de lealdade. Nessas condições, a criança tende a acreditar no que Ihe foi imposto como sendo a sua verdade, elaborando um registro psíquico de uma abuso sexual, o que promove a confusão entre realidade e fantasia, compreendido como uma forma de violência psicológica.

As falsas alegações, portanto, abrangem a fabricação intencional, crença equivocada de que a criança foi abusada e/ou erro de interpretação ou distorção na averiguação dos sinais e análise do contexto histórico-familiar, perpassando, necessariamente, o trabalho do psicólogo.

Matéria complexa, instigante, sendo um verdadeiro desafio aos profissionais que atuam na avaliação de casos de suspeita de abuso sexual contra a criança, tanto pelas implicações na vida de crianças e de seus familiares, quanto éticas. Nesse sentido, é primordial o reconhecimento dos limites pessoais e daqueles que toda ciência possui, a fim de que o psicólogo possa oferecer serviços de qualidade nos diversos espaços e contextos, tendo sempre em vista a qualidade de vida da população.

\section{Referências Bibliográficas}

Amazarray, M. R.; Koller, S. H. Alguns aspectos observados no desenvolvimento de crianças vítimas de abuso sexual. Psicologia Reflexão \& Crítica , Porto Alegre, v. 11, n. 3, p. 559-578, 1998. AMENDOLA, M. F. Mães que Choram: avaliação psicodiagnóstica de mães de crianças vítimas de abuso sexual. In: PRADO, M.C.C.A. (org.) O Mosaico da Violência - a perversão na vida cotidiana. São Paulo: Vetor, 2004, p. 103-169. 
ARZENO, M. E. G. Psicodiagnóstico Clínico: novas contribuições. Porto Alegre: Artes Médicas, 1995.

ASSIS, S. G. Crianças e adolescentes violentados: passado, presente e perspectivas para o futuro. Cadernos de Saúde Pública, Rio de Janeiro, v. 10, supl.1, p. 126-134, 1994.

BRASI L. Novo Código Civil: Lei 10.406/02. 2. ed. Organizado por J osé Guilhermes Soares Filho. Rio de Janeiro: DP\&A, 2003.

BRASIL. Estatuto da Criança e do Adolescente: Lei 8.069, de 13 de julho de 1990. Coleção Legislação Brasileira, v. 11. Rio de Janeiro: DP\&A, 2003.

BRITO, L. M. T. De competências e convivências: caminhos da Psicologia junto ao Direito de Família. In: _____. (org.) Temas de Psicologia J urídica. 3. ed. Rio de Janeiro: Relume-Dumará, 2002a., p. 171-186.

BRITO, L. M. T. I mpasses na condição da guarda e da visitação - O Palco da Discórdia. In: Anais do III Congresso Brasileiro de Direito de Família . Belo Horizonte: IBDFAM/Del Rey, 2002b., p. 433-448.

Bruck, M., Ceci, S. J.; Shuman, D. W. Disclosure of child sexual abuse: What does the research tell us about the ways that children tell? Psychology, Public Policy and the Law , Washington, DC, v. 11, n. 1, p. 194-226, 2005.

CAMINHA, R. M. A Violência e seus danos à criança e ao adolescente. In: AMENCAR (org.) Violência Doméstica . Brasília: UNICEF, 2000. p. 43-60.

CÁRDENAS, E. J. El Abuso de la Denuncia de Abuso. La Ley, Madrid, ano XLIX, n. 178, p. 1-3, 2000.

CECl, S. J., BRUCK, M.; ROSENTHAL, R. Children's allegations of sexual abuse: forensics and scientific issues: a reply to commentators. Psychology, Public Policy and Law , Washington, DC v. 1, n. 2, p. 494-520, 1995.

CECl, S. J.; BRUCK, M. Jeopardy in the Courtroom : a scientific analysis of children's testimony. 6. ed. Washington, DC: American Psychological Association (APA Books), 2002.

CECl, S. J.; HEMBROOKE, H. Expert witnesses in child abuse cases : what can and should be said in court. Washington, DC: American Psychological Association (APA Books), 1998.

CHAUI, M. S. Convite à Filosofia . Ed. Ática: São Paulo, 2000.

COLEMAN, L.; CLANCY, P. E. Has a child been molested?: the disturbing facts about current methods of investigating child sexual abuse accusations. Walnut Creek, CA: Berkeley Creek Productions, 1999.

COMEL, D. D. Poder familiar: titularidade. Inconstitucionalidade da primeira parte do caput do art. 1.631 do Código Civil. J us Navigandi Teresina, ano 8, n. 363, 5 jul. 2004. Disponível em: 
<http://jus2.uol.com.br/doutrina/texto.asp?id=5414>. Acesso em: 12 jan. 2005.

DE YOUNG, M. A conceptual model for judging the truthfulness of a young child's allegation of sexual abuse. American J. Orthopsychiatry , Washington, DC, v. 56, n. 4, p. 550-559, 1986.

Faleiros, E. T. S.; Campos, J. O. Repensando os conceitos de violência, abuso e exploração sexual de crianças e de adolescentes. CECRIA, Departamento da Criança e Adolescente da Secretaria Nacional de Direitos Humanos do Ministério da Justiça, Brasília, 2000.

FALEIROS, V. P. Redes de Exploração e Abuso Sexual e redes de Proteção . Brasília: Anais do IX Congresso Brasileiro de Assistentes Sociais, v. 1, p. 267-272, jul. 1998.

FARINATTI, F.; BIAZUS, D. B.; LEITE, M. B. Pediatria Social - a criança maltratada. Curitiba: Medsi, 1993.

FINKELHOR, D. What's wrong with sex between adults and children? Ethics and the problem of sexual abuse. American Journal of Orthopsychiatry, Washington, DC, v. 49, p. 692-697, 1979.

FLORES, R. Z. Definir e medir o que são abusos sexuais. In: LEAL, M.F.P.; CÉSAR, M.A. (org.) Indicadores de Violência Intrafamiliar e Exploração Sexual comercial de crianças e Adolescentes (relatório final da oficina). Brasília, CECRIA, 1998.

Furniss, T. Abuso Sexual da Criança: uma abordagem multidisciplinar. 2. ed. Porto Alegre: Artes Médicas, 2002.

GARBARINO, J.; GILLIAM, G. Understanding Abusive Families . Massachusetts: Lexing Books, 1981.

GARDNER, R. A. Sex Abuse Hysteria : Salem Witch Trials Revisited. Cresskill. New Jersey: Creative Therapeutics, 1991.

GARDNER, R. A. The Parental Alienations Syndrome. A guide for mental health and legal professionals. 2 ed. Cresskill, New Jersey: Creative Therapeutics, 1992.

Gonçalves, H.S. Infância e violência doméstica: um tema da modernidade In: Brito, L.M.T. (org.). Temas de Psicologia J urídica . Rio de J aneiro: Relume-Dumará, 1999, p. 133-160.

Gonçalves, H.S. Infância e Violência no Brasil . Rio de Janeiro: NAU editora e FAPERJ, 2003.

Gonçalves, H.S.; Ferreira, A. L. A notificação da violência intrafamiliar contra crianças e adolescentes por profissionais de saúde. Cadernos de Saúde Pública, Rio de Janeiro, v. 18, n. 1, p. 315-319, 2002.

Green, A. H. Child sexual abuse: Immediate and long-term effects and intervention. Journal of the American Academy Child and Adolescent Psychiatry, New Haven, CT, v. 32, n. 5, p. 890-902, 1993.

HABIGZANG, L. F.; CAMINHA, R. M. Abuso Sexual contra crianças e adolescentes - conceituação e intervenção clínica. São Paulo: Casa do Psicólogo, 2004. 
Haugaard, J. J.; Repucci, D. The Sexual Abuse of Children : A Comprehensive Guide to Current Knowledge and Intervention Strategies (Social and Behavioral Science Series). San Francisco: Jossey - Bass Pub, 1988.

JUNQUEIRA, M. F. O abuso sexual e a prática clínica : sexualidade e desamparo. Psicologia Clínica, Rio de Janeiro, PUC-RJ, v. 10, n. 10, p. 25-42, 1998.

KOLLER, S. H. Violência Doméstica: uma visão ecológica. In: AMENCAR (org.) Violência Doméstica . Brasília: UNICEF, 2000. p. 32-42.

LOWRY, R. Creating Victims - False Charges of Sexual Abuse of Children. National Review, New York, NY, dec. 5, 1994. Disponível em: <http://findarticles.com/p/articles/mi_m1282/is_n23_v46.

Acesso em: 8 mar. 2005.

MI LLER, D. Incesto: O Centro da Escuridão. In: Imber-Black, E e col. Os Segredos na Família e na Terapia de Família . Porto Alegre: Artes Médicas, 2002. p. 185-199.

MINAYO, M. C. S.(org.) Pesquisa social : teoria, método e criatividade. 13. ed. Petrópolis: Vozes, 1999.

MIRANDA JR., H. C. Psicanálise e avaliação psicológica no âmbito jurídico. In: SHINE, S. (org.). Avaliação Psicodiagnóstica e Lei. Adoção, Vitimização, Separação Conjugal, Dano Psíquico e outros temas. São Paulo: Casa do Psicólogo, 2005. p. 159-174.

NJ AINE, K.; SOUZA, E. R.; MINAYO, M. C. S.; ASSIS, S. G. A produção da (des)informação sobre violência: análise de uma prática discriminatória. Cadernos de Saúde Pública , Rio de Janeiro, v. 13, n. 3, p. 405-414, 1997.

NOGUEI RA, S. E. Abuso Sexual Infantil: A Importância da Palavra da Criança. In: Anais do VII Fórum da Residência em Psicologia ClínicoInstitucional. Revista Práxis e Formação: as várias modalidades de intervenção do Psicólogo, Rio de Janeiro, UERJ, Instituto de Psicologia, 2002, p. 91-101.

NOGUEIRA, S. E.; SÁ, M. L. B. P. Atendimento psicológico a crianças vítimas de abuso sexual: alguns impasses e desafios. In: PRADO, M.C.C.A. (org.) O Mosaico da Violência - a perversão na vida cotidiana. São Paulo: Vetor, 2004. p. 47-102.

PIAGET, J. O juízo moral na criança . São Paulo: Summus, 1994.

REVISTA CRESCER - em família. Entrevista: Contra o abuso Edição 128. Rio de Janeiro: Editora Globo, jul. 2004.

REVISTA ESCOLA - Comportamento. Mentira ou fantasia? Edição 176. São Paulo: Editora Abril, out. 2004.

RIBEIRO, M. A., FERRIANI, M. G. C., REIS, J. N. Violência sexual contra crianças e adolescentes: características relativas à vitimização nas relações familiares. Cadernos de Saúde Pública , Rio de Janeiro, v. 20, n. 2, p. 456-464, 2004. 
Rouyer, M. As Crianças Vítimas, consequências a curto e médio prazo. In: Gabel, M. Crianças vítimas de abuso sexual. São Paulo: Summus, 1997. p. 62-71.

SANDERSON, C. Abuso Sexual em Crianças . São Paulo: M. Books, 2005.

Schacter, D. I. Os sete pecados da memória - como a mente esquece e lembra. Rio de Janeiro: Rocco, 2003.

SGROI, S. Handbook of Clinical Intervention in Child Sexual Abuse . Lexington Press. Lexington, Mass Toronto. Lexington books. 1982.

SILVA, M. A. S. Violência contra crianças - quebrando o pacto do silêncio. In: FERRARI, D.; VECINA T. (org.) O Fim do Silêncio na Violência Familiar - Teoria e Prática. São Paulo: Ágora, 2002. p. 73-80.

THOUVENIN, C. A palavra da criança: do íntimo ao social. In: GABEL, M. Crianças vítimas de abuso sexual . São Paulo: Summus, 1997. p. 91-102.

Wallerstein, J. S.; Kelly, J. Sobrevivendo à separação : como pais e filhos lidam com o divórcio. Porto Alegre: Artes Médicas, 1998.

WAKEFIELD, H.; UNDERWAGER, R. Special Problems with Sexual Abuse Cases. In: ZISKIN, J. Coping With Psychiatric and Psychological Testimony . 5. ed. Los Angeles, CA: Law and Psychology Press, 1995, p. 1315-1370.

YEHIA, G. Y. Reformulação do papel do psicólogo no psicodiagnóstico fenomenológico-existencial e sua repercussão sobre os pais. In: ANCONA-LOPEZ, M. (org.) Psicodiagnóstico: processo de intervenção. 3. ed. São Paulo: Cortez, 2002. p. 115-134.

\section{Endereço para correspondência}

Marcia Ferreira Amendola

Hospital Universitário Pedro Ernesto - HUPE, Psicologia, Av. 28 de Setembro, 87, CEP 20551-030, Vila I sabel, Rio de J aneiro-RJ, Brasil

Endereço eletrônico: psi.amendola@gmail.com

Recebido em: 27/09/2007

Aceito para publicação em: 07/07/2008

Editor responsável: Ariane Patrícia Ewald 